\author{
N. G. Forouhi • B. Balkau • K. Borch-Johnsen • \\ J. Dekker · C. Glumer - Q. Qiao · A. Spijkerman • \\ R. Stolk $\cdot$ A. Tabac $\cdot$ N. J. Wareham • \\ On behalf of EDEG
}

\title{
The threshold for diagnosing impaired fasting glucose: a position statement by the European Diabetes Epidemiology Group
}

Received: 14 December 2005 / Accepted: 16 December 2005 / Published online: 9 March 2006

C) Springer-Verlag 2006

\begin{abstract}
The category of IFG was introduced in the late 1990 s to denote a state of non-diabetic hyperglycaemia defined by a fasting plasma glucose (FPG) concentration between 6.1 and $6.9 \mathrm{mmol} / \mathrm{l}$. In 2003 the American Diabetes Association recommended that this diagnostic threshold be lowered to $5.6 \mathrm{mmol} / \mathrm{l}$. The justification for lowering the threshold has been questioned. This simple change in cut-off value creates a pandemic of IFG, with a two- to five-fold increase in the prevalence of IFG across the world. Such a change in threshold has far-reaching public health implications. The European Diabetes Epide-
\end{abstract}

N. G. Forouhi · N. J. Wareham $(\bowtie)$

MRC Epidemiology Unit, Elsie Widdowson Laboratories,

120 Fulbourn Road,

Cambridge, CB1 9NL, UK

e-mail: nick.wareham@mrc-epid.cam.ac.uk

Tel.: +44-1223-330315

Fax: +44-1223-330316

B. Balkau

INSERM U258-IFR69,

Cardiovascular and Epidemiological Epidemiology,

Villejuif, France

K. Borch-Johnsen · C. Glumer

Steno Diabetes Center,

Gentofte, Denmark

J. Dekker · A. Spijkerman

Institute for Research in Extramural Medicine,

VU University Medical Center,

Amsterdam, The Netherlands

Q. Qiao

Diabetes and Genetic Epidemiology Unit,

National Public Health Institute, University of Helsinki,

Helsinki, Finland

R. Stolk

Department of Epidemiology and Bioinformatics University Medical Center, University of Groningen,

Groningen, The Netherlands

A. Tabac

National Centre for Diabetes Care, Diabetes Unit,

Budapest, Hungary miology Group (EDEG) has reviewed the evidence for this lower cut-off point for the definition of IFG and concludes that the previous definition should not be altered. EDEG further recommends that the value of all categorical definitions of non-diabetic hyperglycaemia should be reconsidered.

Abbreviations ADA: American Diabetes Association CVD: cardiovascular disease - DECODE: diabetes epidemiology collaborative analysis of diagnostic criteria in Europe - DESIR: data from an epidemiological study on the insulin resistance syndrome - EDEG: European Diabetes Epidemiology Group - FPG: fasting plasma glucose $\cdot$ HR: hazard ratio - IFG: impaired fasting glucose . $\mathrm{RR}$ : relative risk

\section{Introduction}

The category of IFG was first introduced in the revision of the diagnostic criteria for diabetes when the American Diabetes Association (ADA) in 1997, and the World Health Organization in 1999 recommended that a fasting plasma glucose (FPG) value of $\geq 6.1$ and $<7.0 \mathrm{mmol} / 1 \quad(\geq 110$ and $<$ $126 \mathrm{mg} / \mathrm{dl}$ ) should be used to define this state. The main reason was to create a fasting category which would be analogous to IGT defined according to the 75-g post-load glucose levels. In 2003, the ADA recommended that the threshold for diagnosing IFG should be lowered to $5.6 \mathrm{mmol} / \mathrm{l}$ or $100 \mathrm{mg} / \mathrm{dl}$ [1]. This was justified by the desire to identify similar proportions of the population with IFG and IGT, and to produce equivalent predictive power for progression to diabetes from the IGT and IFG categories.

This recommendation has been re-endorsed in subsequent ADA position statements. However, acceptance of the new criteria has not been universal. At its 2005 Annual Meeting, the European Diabetes Epidemiology Group (EDEG), a subgroup of the European Association for the Study of Diabetes, resolved to review the evidence for lowering the threshold for IFG from $6.1 \mathrm{mmol} / \mathrm{l}$ to 
$5.6 \mathrm{mmol} / 1$ and to make recommendations for use in Europe. This paper summarises this evidence and presents the EDEG recommendations for the threshold for defining IFG.

\section{The relationship between levels of fasting glucose and future risk of diabetes}

A considerable amount of attention in the literature has been paid to comparisons between IFG and IGT and the relative merits of one compared with the other in predicting future diabetes [2, 3]. However, in the context of considering the threshold for defining IFG, these comparison arguments are less clinically relevant because usually in clinical practice risk prediction will occur using only the fasting level without knowledge of the $2 \mathrm{~h}$ value. Thus, what is important is the shape of the risk curve relating levels of fasting glucose to the future risk of incident diabetes.

We examined the magnitude of the association between different thresholds for IFG and diabetes from published data, or derived it from the published data when it was not available directly (Table 1). Overall, the magnitude of the association between diabetes and IFG is greater for IFG defined as FPG $6.1-6.9 \mathrm{mmol} / \mathrm{l}$ than for the new category of FPG 5.6-6.0 mmol/l. The Data from an Epidemiological Study on the Insulin Resistance Syndrome (DESIR) study in France demonstrated this trend in both men and women: diabetes incidence rates per 1,000 person-years for IFG categories of <5.6, 5.6-6.0 and $6.1-6.9 \mathrm{mmol} / 1$ were, respectively, 1.8, 5.7, and 43.2 in men and 0.7, 6.2 and 54.7 in women [4]. Thus, the incidence rate of diabetes in the new IFG group was less than one-seventh of that of the original IFG group. A recent study from rural Italy supports these findings. In a population-based prospective study of 1,441 Italian adults (the Brisighella Heart Study), at 8 years of follow-up, IFG (FPG 6.1-6.9 mmol/l) was significantly associated with incident diabetes, but basal glycaemia under $6.1 \mathrm{mmol} / 1$ was not significantly associated with future diabetes [5]. We found no published evidence that the new lower IFG cut-off point confers any benefit in the identification of future diabetes that is not already identified by the original cut-off point of $6.1 \mathrm{mmol} / \mathrm{l}$. Of course, a lowering of the threshold will improve the sensitivity of IFG as a predictor of diabetes but at the cost of specificity. As we argue later in this paper, deciding where to draw the line is not straightforward. So, what do we know about the shape of the risk curve relating fasting glucose to new-onset diabetes? In a study of 4,721 nondiabetic individuals with a repeat OGTT at 5 years of follow-up, the risk of incident diabetes increased with increasing baseline fasting glucose, but there was little evidence of a threshold effect near $6.1 \mathrm{mmol} / \mathrm{l}$ [6]. A threshold effect, however, is reported in Pima Indians, in whom the risk of diabetes increased gradually over most of the distribution of fasting glucose values, but the incidence rate increased markedly at fasting glucose concentrations above $\sim 100 \mathrm{mg} / \mathrm{dl}(5.6 \mathrm{mmol} / \mathrm{l})$ [7]. It may be that only some populations demonstrate a risk threshold. For European populations there is no evidence of such a threshold. Indeed, recent evidence suggests that higher fasting glucose levels within the normoglycaemic range constitute an independent risk factor for type 2 diabetes among young men [8]. In the large Israeli prospective study of 13,163 healthy men with fasting glucose concentrations

Table 1 Association of incident diabetes with impaired fasting glucose defined by different cut-off points

\begin{tabular}{|c|c|c|c|c|}
\hline Study & Population & $\begin{array}{l}\text { Reference } \\
\text { category }\end{array}$ & $\begin{array}{l}\mathrm{RR}(95 \% \mathrm{CI}) \text { for incident diabetes } \\
\mathrm{IFG} \text { category } 6.1 \text { to }<7.0 \mathrm{mmol} / 1\end{array}$ & $\begin{array}{l}\text { RR }(95 \% \mathrm{CI}) \text { for incident diabetes new } \\
\text { IFG category } 5.6 \text { to }<6.1 \mathrm{mmol} / 1\end{array}$ \\
\hline $\begin{array}{l}\text { Finnish } \\
\text { MONICA } \\
\text { study [31] }\end{array}$ & $\begin{array}{l}\text { Population-based cohort aged } \\
45-64 \text { years }(n=2,593) \\
\text { in Finland with 10-year } \\
\text { follow-up }\end{array}$ & $\begin{array}{l}\text { FPG } \\
<4.9 \mathrm{mmol} / 1\end{array}$ & $6.4(3.51,1.9)$ & $1.9(1.1,3.3)$ \\
\hline $\begin{array}{l}\text { Singapore } \\
\text { study [30] }\end{array}$ & $\begin{array}{l}\text { 8-year follow-up of } 915 \text { adults } \\
\text { with NGT or IGT from the } \\
\text { Singapore IGT study }\end{array}$ & $\begin{array}{l}\text { FPG } \\
<5.6 \mathrm{mmol} / 1\end{array}$ & $55.1(20.4,148.7)$ & $12.4(4.7,32.8)$ \\
\hline $\begin{array}{l}\text { Ely study, } \\
\text { UK [33] }\end{array}$ & $\begin{array}{l}\text { Population-based cohort study } \\
\text { of individuals aged } \\
40-69 \text { years }(n=1,071) \text { in UK } \\
\text { with 5-year follow-up }\end{array}$ & $\begin{array}{l}\text { FPG } \\
<5.4 \mathrm{mmol} / 1\end{array}$ & $15.4(2.1,115.7)$ & $3.6(0.4,32.0)$ \\
\hline
\end{tabular}

FPG Fasting plasma glucose 
lower than $5.6 \mathrm{mmol} / \mathrm{l}$ at baseline, the 6-year risk of incident diabetes increased progressively with FPG concentrations of $4.83 \mathrm{mmol} / \mathrm{l}$ or more compared with those in the bottom quintile $(\mathrm{FPG}<4.5 \mathrm{mmol} / \mathrm{l})[8]$.

On the basis of this evidence, it appears that fasting plasma glucose levels represent a continuum of risk for diabetes. Consequently, the choice of a level of fasting glucose to categorise people into groups based on the future risk of diabetes is somewhat arbitrary since the population does not divide neatly into those with and without risk. Even if risk were to be dichotomous, progression to diabetes should not be the only foundation on which risk strata are based. The public health consequences of diabetes are mostly related to cardiovascular complications and thus it is important to study how non-diabetic hyperglycaemia is associated not just with progression to diabetes but also with cardiovascular incidence and mortality.

\section{Relationship between raised levels of fasting glucose and future risk of cardiovascular disease or death}

A continuum of cardiovascular disease (CVD) risk and both total and CVD mortality with increasing postchallenge glucose has been shown consistently in multiple studies, but the association of this risk with fasting glucose has been less well defined. The Diabetes Epidemiology Collaborative Analysis Of Diagnostic Criteria in Europe (DECODE) study among 22 European cohorts (and nearly 30,000 participants) reported that there was no glycaemic threshold for either fasting or $2 \mathrm{~h}$ glucose above which total mortality increased sharply [9]. Both very low and high fasting glucose levels were associated with total and CVD death in a J-shaped relationship, but for $2 \mathrm{~h}$ glucose and CVD mortality there was a graded association [9]. A recent study among 23,755 men in Taiwan found that, consistent with the DECODE findings, there was a J-shaped association between all-cause mortality and fasting blood glucose [10]. Recent data on 237,468 individuals in the AsiaPacific Cohort Collaboration found that there was a positive log-linear association between usual fasting glucose (i.e. fasting glucose corrected for regression dilution bias) and the risk of total stroke and ischaemic heart disease events. The association was continuous down to a glucose level of $4.9 \mathrm{mmol} / \mathrm{l}$, without a threshold effect [11]. A recent meta-analysis of 38 prospective studies reported that the post-challenge blood glucose level in the non-diabetic range had a linear relationship with CVD risk. However, the association with fasting glucose was non-linear, with a possible threshold effect at around $5.6 \mathrm{mmol} / \mathrm{l}$ [12]. A caveat is that the studies included in the meta-analysis were very heterogeneous: different CVD end-points were measured; glucose levels were based on highest and lowest categories which were not uniform across studies; and although CVD risk factors were adjusted for, history of previous CVD was not explicitly adjusted for in the analyses.
Further evidence against lowering the threshold of IFG definition comes from a Taiwanese study [10]. IFG, when defined as $6.1-6.9 \mathrm{mmol} / \mathrm{l}$, was associated with a significant increase in CVD and/or diabetes mortality (the relative risk [RR] ranging between 1.3 and 7.0). However, when IFG was defined as $5.6-6.9 \mathrm{mmol} / \mathrm{l}$, the predictive value of IFG was abolished and the mortality risks were diminished substantially because of the inclusion of the 5.6-6.1 $\mathrm{mmol} / \mathrm{l}$ group, in which the RR ranged nonsignificantly between 0.9 and 2.5 [10]. The findings were replicated for total mortality in the Baltimore Longitudinal Study of Aging [13]. Among 1,236 men followed for 13 years, the risk of mortality did not increase until the FPG exceeded $6.1 \mathrm{mmol} / \mathrm{l}$. The RR for mortality was $1.03(95 \%$ CI 0.80-1.32) in the FPG group 5.6-6.1 mmol/1, whereas the risk was elevated by $40 \%$ in the FPG group $6.1-$ $6.9 \mathrm{mmol} / \mathrm{l}$ (RR 1.41, 1.01-1.97), the authors finding no support for the lowering of IFG to $5.6 \mathrm{mmol} / \mathrm{l}$ from $6.1 \mathrm{mmol} / \mathrm{l}$ for the outcome of mortality [13]. Nearly identical findings were reported from the Dutch Hoorn study, in which the age- and sex-adjusted RR for CVD mortality was $1.43(0.79-2.60)$ in the FPG group 6.1$6.9 \mathrm{mmol} / \mathrm{l}$, but $0.63(0.34-1.19)$ in the new IFG group of 5.6-6.0 mmol/1 [14]. For the outcome of incident CVD events, the only data comparing IFG thresholds come from a prospective study of secondary prevention in women with established coronary heart disease (CHD) [15]. They reported that women with IFG according to the 1997 ADA definition (FPG 6.1-6.9 mmol/l) had an increased risk of any CHD event (hazard ratio [HR] 1.37, 95\% CI 1.08-1.74), but those with the modified 2003 ADA definition (FPG 5.6-6.9 mmol/l) were not at increased risk (HR 1.09, 0.90-1.34), nor were women in the fasting glucose range of 5.6-6.0 mmol/1 (HR 0.90, 0.73-1.12) [15], further undermining the appropriateness of the lowering of the IFG threshold.

Although there are few studies relating non-diabetic hyperglycaemic categories to CVD outcomes, IGT, but not IFG, has consistently been associated with CHD risk factors. The Risk factors in IGT for Atherosclerosis and Diabetes (RIAD) study reported that the intima-media thickness (IMT) of the common carotid artery (as a marker of atherosclerosis) in individuals with isolated IFG did not differ from that in controls with NGT, but that the IMT was greater in those with isolated IGT and combined IFG and IGT [16]. They also found that an FPG below $7.0 \mathrm{mmol} / \mathrm{l}$ was not related to IMT, but post-challenge glucose was predictive of IMT in individuals with IFG $(6.1-7.0 \mathrm{mmol} / \mathrm{l})$ and in those with normoglycaemia (FPG $<6.1 \mathrm{mmol} / \mathrm{l})$ [17]. Both the Baltimore Longitudinal Study on Aging [18] and an Italian study [19] reported a higher prevalence of CHD risk factors among those with IGT but not among those with IFG alone, when compared with normoglycaemic individuals. This was the case whether the original (FPG 6.1-6.9 $\mathrm{mmol} / \mathrm{l}$ ) or the modified (FPG 5.6-6.9 mmol/l) definition of IFG was used [18, 19].

In summary, existing evidence suggests that no benefit will be gained by lowering the IFG threshold in the context of risk association with CVD or mortality. 


\section{Evidence that reduction in fasting glucose levels lowers the risk of diabetes or cardiovascular disease}

There is convincing evidence from primary prevention clinical trials that lifestyle interventions, including weight loss and increased physical activity, or drug therapy with metformin or acarbose are effective in delaying the onset of diabetes in people with IGT [20-23]. There is also emerging evidence for the possible primary prevention of CVD among those with IGT. The multicentre STOPNIDDM (Study to prevent non-insulin-dependent diabetes mellitus) study reported a $49 \%$ relative risk reduction (and $2.5 \%$ absolute risk reduction) for cardiovascular events with acarbose treatment in those with IGT [24]. In contrast, a recent report of the US Diabetes Prevention Program (DPP) did not replicate this finding for metformin, but there was a risk reduction in hypertension with intensive lifestyle intervention [25].

There are no similar data for the effectiveness of lifestyle or drug interventions in individuals with IFG. The only published data are from the Fasting Hyperglycaemia Study, in which 227 self-referred non-diabetic individuals with raised plasma glucose $(5.5-7.7 \mathrm{mmol} / \mathrm{l})$ were evaluated $[26,27]$. Reinforced healthy lifestyle advice did not achieve sustained lifestyle changes, as measured by body weight and did not result in reduction in glycaemia at the 1year follow-up when compared with a programme of basic healthy lifestyle advice [26]. Sulfonylurea therapy improved glycaemic control and beta cell function at 1 year, but progression to diabetes was not measured [27]. Currently, therefore, there is no evidence of the primary prevention of diabetes or CVD among those with IFG.

\section{The benefits and harm of labelling individuals with raised fasting glucose}

There is no published evidence that labelling individuals with IFG will provide clinical or public health benefits. One might speculate that those who are labelled with the diagnosis of IFG might adopt healthy lifestyle advice, but there are no data demonstrating benefit in people with fasting plasma glucose of 5.6-6.9 mmol/1 (100-126 mg/dl) who do not also have IGT. There might be potential harm in labelling people; for example, life or medical insurance premiums could potentially increase and IFG could be considered as a pre-existing condition, and thus costs incurred for subsequent diabetes may not be paid [28].

In general, those who have IFG (whether in the range of 6.1-6.9 $\mathrm{mmol} / 1$ or $5.6-6.0 \mathrm{mmol} / \mathrm{l}$ ) concurrently have several features of the metabolic syndrome, such as dyslipidaemia, hypertension and central obesity. The direct clinical management of these conditions may be necessary, but is not dependent upon labelling a person as having IFG.

\section{The scale of the rise in prevalence of IFG with the proposed change in diagnostic threshold}

It is a truism that when a diagnostic threshold is lowered, more people will be classified as having that condition. Extrapolating from the National Health and Nutrition Examination Survey (NHANES) data, the prevalence of IFG in the US population would increase from $6.7 \%(\sim 12$ million people) to $24.1 \%$ ( $\sim 44$ million people) with the lower threshold, particularly among the 20 - to 50 -year-olds (a greater than fivefold increase from 3.1 to $17.3 \%$ ) [28] The lowered threshold would increase the prevalence of IFG from 11.8 to $37.6 \%$ in Denmark, from 15.9 to $45.2 \%$ in France, from 11.2 to $26.7 \%$ in urban China, from 10.6 to $37.6 \%$ in urban India, from 9.5 to $28.5 \%$ in the USA [29] and from 9.5 to $32.3 \%$ in Singapore [30]. Thus, lowering the threshold for diagnosis of IFG increases the prevalence of IFG two to fivefold in most populations. The implications of this two to fivefold increase in prevalence are not known. To our knowledge, no modelling has been undertaken to assess the public health impact of the increase in prevalence of IFG that would follow a lowering of the diagnostic cut-off point for IFG.

\section{The rationale for the lower cut-off point for IFG}

In the ADA 2003 follow-up report the Expert Committee stated that the rationale for lowering the cut-off point from 110 to $100 \mathrm{mg} / \mathrm{dl}(6.1-5.6 \mathrm{mmol} / \mathrm{l})$ was based on examining the receiver operating characteristic (ROC) curve of the ability of various baseline levels of FPG to predict diabetes. They reported that the FPG value at the point on the ROC curve closest to the ideal of $100 \%$ sensitivity and $100 \%$ specificity over the glycaemic range of $81-126 \mathrm{mg} / \mathrm{dl} \quad(4.5-7.0 \mathrm{mmol} / \mathrm{l})$ was $103 \mathrm{mg} / \mathrm{dl}$ $(5.7 \mathrm{mmol} / \mathrm{l})$ in a Dutch population, $97 \mathrm{mg} / \mathrm{dl}(5.4 \mathrm{mmol} /$ 1) in a Pima Indian group, $94 \mathrm{mg} / \mathrm{dl}(5.2 \mathrm{mmol} / \mathrm{l})$ in a Mauritius population and $94 \mathrm{mg} / \mathrm{dl}(5.2 \mathrm{mmol} / \mathrm{l})$ in a San Antonio population. Based on this, the Expert Committee recommended that changing the cut-off point to $100 \mathrm{mg} / \mathrm{dl}$ $(5.6 \mathrm{mmol} / \mathrm{l})$ would optimise its sensitivity and specificity for predicting future diabetes. This analysis assumes that all populations show the same relationship between fasting glucose and diabetes incidence, which we have argued may not be the case. It also assumes that optimising both sensitivity and specificity is the desirable strategy. The decision about where to draw any cut-off point on a continuous scale relates to the relative harm from being a false positive compared with a false negative. This in turn is dependent upon the treatment consequences that follow from attribution of a label. One cannot divorce the issue of cut-off point evaluation from the evidence of efficacy of intervention for those who fall above the line. At a time when there is no evidence of long-term benefit, the balance must lie with maximising specificity, and this argues for leaving the threshold unaltered. 


\section{Summary and recommendations}

Identifying and labelling those at higher risk of diabetes does not necessarily ensure that their health will be improved. Currently there is no convincing evidence that the attribution of the label of IFG, even without a change in its diagnostic threshold, will achieve better health outcomes.

The ADA Expert Committee on the Diagnosis and Classification of Diabetes acknowledge that 'the factors that should influence the choice of the cut point are not currently known for IFG. For example, we do not yet know the total benefit or the total cost to an individual who is designated at risk for diabetes by either test, by any criterion' [1]. In our view it is not logical to lower the threshold for diagnosis and create a pandemic of IFG, without serious consideration of its impact on the individual or the health-care system.

Throughout this paper we have referred to raised glucose in people without diabetes as "non-diabetic hyperglycaemia'. We believe this descriptive term is preferable to others in use, such as 'dysglycaemia' and 'impaired fasting glucose', which are misnomers. We would also suggest avoidance of the term 'pre-diabetes' since this implies that if one has IFG or IGT, then one is in a state that will definitely progress to diabetes, which is not the case. Many people revert to normoglycaemia on subsequent testing after a first test showing raised glucose levels, and there is no fixed state of pre-diabetes.

EDEG recommends that we retain the originally suggested diagnostic cut-off point for IFG at $6.1 \mathrm{mmol} / \mathrm{l}$. At the same time, EDEG recommends a review of the utility of categorical labels for non-diabetic hyperglycaemia. It may be timely to define risk in terms of glucose as a continuous variable. EDEG further recommends a systematic study of the importance and relevance of IFG to clinical end-points through well-planned research studies. These should include intervention trials of lifestyle and drug interventions in adults with non-diabetic hyperglycaemia in the primary prevention of diabetes. We also recommend that current and future trials should focus on CVD outcomes as well as progression to diabetes.

\section{References}

1. Genuth S, Alberti KG, Bennett P et al (2003) Follow-up report on the diagnosis of diabetes mellitus. Diabetes Care 26:3160-3167

2. de Vegt F, Dekker JM, Jager A et al (2001) Relation of impaired fasting and postload glucose with incident type 2 diabetes in a Dutch population: the Hoorn Study. JAMA 285:2109-2113

3. Shaw JE, Zimmet PZ, de Court et al (1999) Impaired fasting glucose or impaired glucose tolerance. What best predicts future diabetes in Mauritius? Diabetes Care 22:399-402

4. Balkau B, Hillier T, Vierron E et al (2005) Comment to: BorchJohnsen K, Colagiuri S, Balkau B et al (2004) Creating a pandemic of prediabetes: the proposed new diagnostic criteria for impaired fasting glycaemia. Diabetologia 47:1396-1402. Diabetologia 48:801-802
5. Cicero AF, Dormi A, Nascetti S et al (2005) Relative role of major risk factors for type 2 diabetes development in the historical cohort of the Brisighella Heart Study: an 8-year follow-up. Diabet Med 22:1263-1266

6. Shaw JE, Zimmet PZ, Hodge AM et al (2000) Impaired fasting glucose: how low should it go? Diabetes Care 23:34-39

7. Gabir MM, Hanson RL, Dabelea D et al (2000) The 1997 American Diabetes Association and 1999 World Health Organization criteria for hyperglycemia in the diagnosis and prediction of diabetes. Diabetes Care 23:1108-1112

8. Tirosh A, Shai I, Tekes-Manova D et al (2005) Normal fasting plasma glucose levels and type 2 diabetes in young men. $\mathrm{N}$ Engl J Med 353:1454-1462

9. The DECODE Study Group (2003) Is the current definition for diabetes relevant to mortality risk from all causes and cardiovascular and noncardiovascular diseases? Diabetes Care 26:688-696

10. Wen CP, Cheng TY, Tsai SP et al (2005) Increased mortality risks of pre-diabetes (impaired fasting glucose) in Taiwan. Diabetes Care 28:2756-2761

11. Lawes CM, Parag V, Bennett DA et al (2004) Blood glucose and risk of cardiovascular disease in the Asia Pacific region. Diabetes Care 27:2836-2842

12. Levitan EB, Song Y, Ford ES et al (2004) Is nondiabetic hyperglycemia a risk factor for cardiovascular disease? A meta-analysis of prospective studies. Arch Intern Med $164: 2147-2155$

13. Sorkin JD, Muller DC, Fleg JL et al (2005) The relation of fasting and $2 \mathrm{~h}$ postchallenge plasma glucose concentrations to mortality: data from the Baltimore Longitudinal Study of Aging with a critical review of the literature. Diabetes Care 28:2626-2632

14. de Vegt F, Dekker JM, Ruhe HG et al (1999) Hyperglycaemia is associated with all-cause and cardiovascular mortality in the Hoorn population: the Hoorn Study. Diabetologia 42:926-931

15. Kanaya AM, Herrington D, Vittinghoff E et al (2005) Impaired fasting glucose and cardiovascular outcomes in postmenopausal women with coronary artery disease. Ann Intern Med 142:813-820

16. Hanefeld M, Temelkova-Kurktschiev T, Schaper F et al (1999) Impaired fasting glucose is not a risk factor for atherosclerosis. Diabet Med 16:212-218

17. Hanefeld M, Koehler C, Henkel E et al (2000) Post-challenge hyperglycaemia relates more strongly than fasting hyperglycaemia with carotid intima-media thickness: the RIAD Study. Risk factors in impaired glucose tolerance for atherosclerosis and diabetes. Diabet Med 17:835-840

18. Blake DR, Meigs JB, Muller DC et al (2004) Impaired glucose tolerance, but not impaired fasting glucose, is associated with increased levels of coronary heart disease risk factors: results from the Baltimore Longitudinal Study on aging. Diabetes 53:2095-2100

19. Vaccaro O, Riccardi G (2005) Changing the definition of impaired fasting glucose: impact on the classification of individuals and risk definition. Diabetes Care 28:1786-1788

20. Tuomilehto J, Lindstrom J, Eriksson JG et al (2001) Prevention of type 2 diabetes mellitus by changes in lifestyle among subjects with impaired glucose tolerance. $\mathrm{N}$ Engl J Med 344:1343-1350

21. Knowler WC, Barrett-Connor E, Fowler SE et al (2002) Reduction in the incidence of type 2 diabetes with lifestyle intervention or metformin. N Engl J Med 346:393-403

22. Pan XR, Li GW, Hu YH et al (1997) Effects of diet and exercise in preventing NIDDM in people with impaired glucose tolerance. The Da Qing IGT and Diabetes Study. Diabetes Care 20:537-544

23. Chiasson JL, Josse RG, Gomis R et al (2002) Acarbose for prevention of type 2 diabetes mellitus: the STOP-NIDDM randomised trial. Lancet 359:2072-2077 
24. Chiasson JL, Josse RG, Gomis R et al (2003) Acarbose treatment and the risk of cardiovascular disease and hypertension in patients with impaired glucose tolerance: the STOPNIDDM trial. JAMA 290:486-494

25. Ratner R, Goldberg R, Haffner S et al (2005) Impact of intensive lifestyle and metformin therapy on cardiovascular disease risk factors in the diabetes prevention program. Diabetes Care 28:888-894

26. Dyson PA, Hammersley MS, Morris RJ et al (1997) The Fasting Hyperglycaemia Study: II. Randomized controlled trial of reinforced healthy-living advice in subjects with increased but not diabetic fasting plasma glucose. Metabolism 46:50-55

27. Karunakaran S, Hammersley MS, Morris RJ et al (1997) The Fasting Hyperglycaemia Study: III. Randomized controlled trial of sulfonylurea therapy in subjects with increased but not diabetic fasting plasma glucose. Metabolism 46:56-60

28. Davidson MB, Landsman PB, Alexander CM (2003) Lowering the criterion for impaired fasting glucose will not provide clinical benefit. Diabetes Care 26:3329-3330
29. Borch-Johnsen K, Colagiuri S, Balkau B et al (2004) Creating a pandemic of prediabetes: the proposed new diagnostic criteria for impaired fasting glycaemia. Diabetologia 47:1396-1402

30. Tai ES, Goh SY, Lee JJ et al (2004) Lowering the criterion for impaired fasting glucose: impact on disease prevalence and associated risk of diabetes and ischemic heart disease. Diabetes Care 27:1728-1734

31. Qiao Q, Lindstrom J, Valle TT et al (2003) Progression to clinically diagnosed and treated diabetes from impaired glucose tolerance and impaired fasting glycaemia. Diabet Med 20:1027-1033

32. Wang JJ, Yuan SY, Zhu LX et al (2004) Effects of impaired fasting glucose and impaired glucose tolerance on predicting incident type 2 diabetes in a Chinese population with high postprandial glucose. Diabetes Res Clin Pract 66:183-191

33. Wareham NJ, Byrne CD, Williams R et al (1999) Fasting proinsulin concentrations predict the development of type 2 diabetes. Diabetes Care 22:262-270 